\title{
Magnesium: does it reduce ischemia/reperfusion injury in an adnexal torsion rat model?
}

This article was published in the following Dove Press journal:

Drug Design, Development and Therapy

\author{
Ebru Celik Kavak' \\ Funda Gulcu Bulmus² \\ Ozgur Bulmus ${ }^{3}$ \\ Salih Burcin Kavak' \\ Nevin Kocaman ${ }^{4}$ \\ 'Department of Obstetrics and \\ Gynecology, ${ }^{2}$ Vocational School of \\ Health Services, ${ }^{3}$ Department of \\ Physiology, ${ }^{4}$ Department of Histology \\ and Embryology, School of Medicine, \\ Firat University, Elazig, Turkey
}

Aim: The aim of the present study was to assess the protective effects of magnesium sulfate $\left(\mathrm{MgSO}_{4}\right)$ on ischemia/reperfusion $(\mathrm{I} / \mathrm{R})$ induced ovarian damage in a rat ovarian torsion model. Methods: Forty-two female Sprague Dawley rats were included in the study. They were divided into six groups as Group 1, sham; Group 2, bilateral ovarian torsion; Group 3, bilateral ovarian torsion-detorsion; Group 4, $\mathrm{MgSO}_{4}$-sham; Group 5, $\mathrm{MgSO}_{4}$-bilateral ovarian torsion; Group 6, bilateral ovarian torsion- $\mathrm{MgSO}_{4}$-detorsion. Both torsion and detorsion periods lasted 3 hours. In Groups 4, 5 and $6, \mathrm{MgSO}_{4}(600 \mathrm{mg} / \mathrm{kg})$ was administered by intraperitoneal route 30 minutes before sham operation, torsion and detorsion, respectively. At the end of the study period, both ovaries were removed. One of the ovaries was used for histopathological analyses and the other for biochemical analyses.

Results: In the torsion-detorsion group, all the histopathological scores were higher compared to the sham and torsion only group $(p<0.05)$. Administration of $\mathrm{MgSO}_{4}$ only caused significant decrease in the inflammatory cell scores of the torsion-detorsion group $(p<0.05) . \mathrm{MgSO}_{4}$, whether given before torsion or before detorsion, suppressed malondialdehyde levels when compared to the untreated groups ( $p<0.01$ and $p<0.001$, respectively). Glutathione peroxidase activities were significantly higher in the $\mathrm{MgSO}_{4}$ applied torsion and detorsion groups than Groups 2 and 3 ( $p<0.05$, for both). Administration of $\mathrm{MgSO}_{4}$ also caused an increase in glutathione levels in the torsion and detorsion groups compared to the torsion only and detorsion only groups ( $p<0.05$, for both). Also, total oxidant status levels decreased in the $\mathrm{MgSO}_{4}$ applied torsion and detorsion groups compared to the untreated corresponding ones $(p<0.01$ and $p<0.001$, respectively). $\mathrm{MgSO}_{4}$ significantly decreased the Oxidative Stress Index levels in the torsion-detorsion group compared to Group $2(p<0.001)$.

Conclusion: Histopathological and biochemical analysis revealed that prophylactic treatment with $\mathrm{MgSO}_{4}$ reduces the changes observed in $\mathrm{I} / \mathrm{R}$ injury in a rat model.

Keywords: ovarian torsion, ischemia/reperfusion injury, magnesium sulfate

\section{Introduction}

Ovarian torsion has been described as rotation of the adnexa around its vascular axis. It is a rarely encountered surgical emergency and requires prompt diagnosis and treatment. Clinical presentation is non-specific and there are often significant delays between the onset of symptoms and operative intervention. ${ }^{1}$ For all age groups, traditional management was resection of the ischemic-appearing ovary because of the theoretical risk of thromboembolism, the concern of associated malignancy and the belief that a grossly blue-black and hemorrhagic adnexa was non-viable. Long-term analysis of the cases treated by detorsion revealed that the method is safe and can save the ovary. So, management has changed and today laparoscopic detorsion as soon as possible is the preferred method in premenopausal women. ${ }^{2}$
Correspondence: Ebru Celik Kavak

Department of Obstetrics and Gynecology, School of Medicine, Firat University, 23100 Elazig, Turkey Tel +904242333555

Fax +904242379138

Email eckavak@gmail.com
Drug Design, Development and Therapy 2018:12 409-4I5

(c) (1) (-) ๑ 2018 Celik Kavak et al. This work is published and licensed by Dove Medical Press Limited. The full terms of this license are avalabble at https://www.dovepress.com/terms.php cc. hereby accept the Terms. Non-commercial uses of the work are permitted without any further permisision from Dove Medical Press Limited, provided the work is properly atributed. For permision for commercial use of this work, please see paragraphs 4.2 and 5 of our Terms (htpps://www.dovepress. com/terms.php). 
Reperfusion by detorsion protects the ovary from ischemic damage. However, during the reperfusion period tissue damage continues because of oxygen-derived free radicals. Due to its results, the torsion-detorsion process is named ischemia/reperfusion (I/R) injury. ${ }^{3}$ Several methods have been tried to prevent this injury. ${ }^{4,5}$ Pharmacologic conditioning with different drugs, having antioxidant and anti-inflammatory properties, has been tested to determine their preventive effect on I/R injury. ${ }^{6,7}$

Magnesium is found in large amounts both in intracellular and extracellular spaces of the body. It is important for numerous physiological events and is used as a therapeutic agent in many areas of medicine like neurology, cardiology, gastroenterology and obstetrics. Magnesium is a powerful antioxidant and a potent anti-inflammatory agent. It inhibits endotoxin-related inflammatory molecule upregulation. ${ }^{8}$ Magnesium is an L-type calcium channel blocker and in this way may decreases calcium overload of the tissue which is an important factor in tissue damage. ${ }^{9}$ Magnesium also provides cellular protection by stabilizing the cell membrane potential and decreasing energy need. ${ }^{10}$

Despite all these important effects, nothing is known about the effect of magnesium on I/R injury of the ovary. We aimed to explore whether $\mathrm{MgSO}_{4}$ could prevent $\mathrm{I} / \mathrm{R}$ injury in rat ovaries.

\section{Materials and methods}

Approval of the study was provided by Firat University local ethics committee for animal research and adhered to guidelines prepared according to EU Directive 2010/63/EU. Experiments were done in a laboratory of the same university. By performing daily vaginal smears, animals showing regular cycles were selected. Forty-two female Sprague Dawley rats weighing between 200 and 250 g, aged 10-12 weeks, were taken and allocated randomly into six groups:

- Group 1: sham $(\mathrm{n}=7)$

- Group 2: bilateral ovarian torsion $(n=7)$

- Group 3: bilateral ovarian torsion-detorsion $(n=7)$

- Group 4: $\mathrm{MgSO}_{4}$-sham (n=7)

- Group 5: $\mathrm{MgSO}_{4}$-bilateral ovarian torsion $(\mathrm{n}=7)$

- Group 6: bilateral ovarian torsion- $\mathrm{MgSO}_{4}$-detorsion $(\mathrm{n}=7)$

Operations were done under anesthesia. Ketamine hydrochloride (50 mg/kg Ketalar; Eczacibasi, Istanbul, Turkey) and xylazine hydrochloride ( $7 \mathrm{mg} / \mathrm{kg}$ Rompun; Bayer, Istanbul, Turkey) were used intramuscularly. Under anesthesia, the animals were placed in prone position on the operating table. The surgical field was shaved, and antisepsis was performed. Two imaginary points, $1-1.5 \mathrm{~cm}$ lateral from the point where the last rib of the animal joined with the vertebrae, were identified on both sides of the back of the animal. New points $1-1.5 \mathrm{~cm}$ caudal to the first points were found and incisions measuring nearly $1 \mathrm{~cm}$ were made. Through passing the muscular layer, the abdominal cavity was reached. The encountered fat layer was carefully removed from the incision out of the abdomen. Next to the fat tissue, the ovary was observed. In Group 1, after 3 minutes the ovary was put back into the abdomen using the same incision and the incision was closed. This procedure was repeated for both sides. After a 3-hour period, euthanasia was performed and both ovaries were taken. In Group 2, bilateral ovarian ischemia was induced by putting a knot that can be opened easily just below the ovary, instead of applying vascular clips. A No 1 silk suture was used for this procedure (Figure 1). Both ovaries were removed 3 hours after placing the knot. In Group 3, after performing ischemia for 3 hours, sutures were removed, and the ovaries were reperfused for 3 hours before removal. In Group 4, $\mathrm{MgSO}_{4}(600 \mathrm{mg} / \mathrm{kg})$ was given intraperitoneally 30 minutes before performing a sham operation. In Group 5 , 30 minutes after intraperitoneal $\mathrm{MgSO}_{4}$ application, ischemia was induced, and the ovaries were taken out after a 3-hour ischemia. In Group 6, an ischemia period lasting 3 hours was performed and $\mathrm{MgSO}_{4}$ was administered intraperitoneally 30 minutes before reperfusion. After the 3-hour reperfusion period both ovaries were taken out. In all groups, one ovary was taken for biochemical analysis and the remaining ovary for histopathological examination. Ovarian tissue samples taken for biochemical analysis were stored at $-80^{\circ} \mathrm{C}$.

\section{Histological examination}

Tissues were fixed in formalin, dehydrated by alcohol, cleared in xylene and put in paraffin blocks. Fragments $5 \mu \mathrm{m}$ thick were cut and hematoxylin and eosin staining was performed. They were analyzed and photographed by the same pathologist in a blind manner using a Leica DM

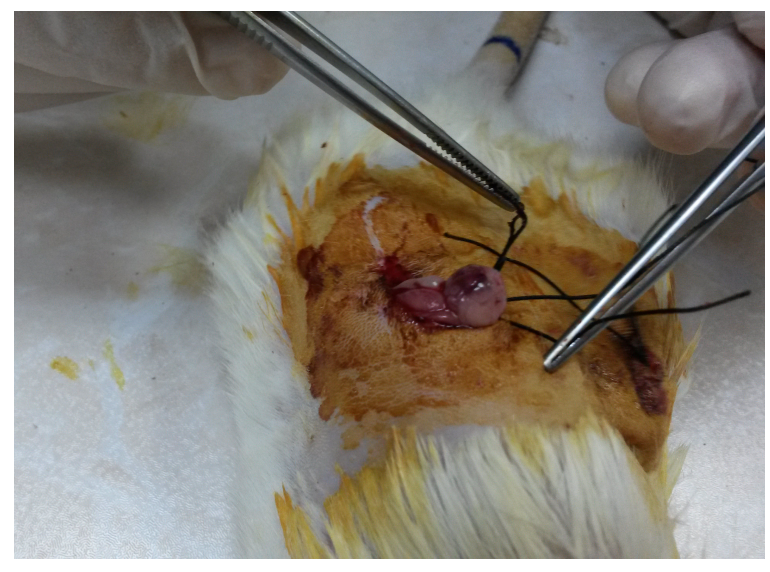

Figure I Torsion model performed in ovaries. 
500 photomicroscope (Leica DFC 295; Leica Microsystems, Wetzlar, Germany). The criteria for ovarian injury were interstitial edema, hemorrhage and polymorphonuclear leukocyte infiltration. Each parameter was scored between 0 and 3, in which 0 indicates absence of abnormal finding and 1, 2 and 3 indicate pathologic findings in $<33 \%, 33 \%-66 \%$ and $>66 \%$ of ovary, respectively. In each group, we added up the results of each parameter and obtained a score.

\section{Biochemical analysis}

The ovarian tissues were homogenized with phosphate buffer $(50 \mathrm{mmol} / \mathrm{L}, \mathrm{pH} 7.0)$ for 3 minutes on ice. They were centrifuged at $10,000 \mathrm{rpm}$ for 10 minutes at $4^{\circ} \mathrm{C}$ to determine malondialdehyde (MDA) and glutathione (GSH) levels and catalase (CAT), glutathione peroxidase (GSH-Px) and superoxide dismutase (SOD) activities. The modified method of Ohkawa et al was used to determine MDA concentrations and results were expressed as nmol/g protein. ${ }^{11}$ Tissue GSH levels were measured by the dithio-nitrobenzoic acid recycling method described by Ellman and the results were given as $\mathrm{nmol} / \mathrm{mg}$ protein. ${ }^{12} \mathrm{CAT}$ activities were determined according to the method of Aebi and results were given as $\mathrm{k} / \mathrm{g}$ protein, where $\mathrm{k}$ is the first-order rate constant. ${ }^{13} \mathrm{GSH}-\mathrm{Px}$ activities were determined by the method of Paglia and Valentine. ${ }^{14}$ The oxidation of NADPH was followed spectrophotometrically at 340 $\mathrm{nm}$ and results were given as U/g protein. SOD activities were measured by the method of Sun et al and a slightly modified method by Durak et al. ${ }^{15,16}$ Tissue SOD activities were given as $\mathrm{U} / \mathrm{g}$ protein. Protein concentrations were determined according to the method of Lowry et al. ${ }^{17}$ Total oxidant status (TOS) and total antioxidant status (TAS) were determined using commercial kits (Rel Assay Diagnostics, Gaziantep, Turkey) on an Advia 2400 analyzer (Siemens Healthcare Diagnostics Inc., Tarrytown, NY, USA). ${ }^{18,19}$ The TOS measurement method was based on the oxidation of ferrous ion-o-dianisidine complex to ferric ion by the oxidants present in the sample. The assay method was calibrated with hydrogen peroxide and results were expressed as $\mu \mathrm{mol} \mathrm{H}_{2} \mathrm{O}_{2} \mathrm{Eq} / \mathrm{g}$ protein. The TAS measurement method was based on the reduction of dark blue-green colored 2,2'-azino-bis(3-ethylbenzothiazoline-6-sulphonic acid) radical to the colorless reduced 2,2'-azino-bis(3-ethylbenzothiazoline6-sulphonic acid) form with the antioxidants present in the sample. The assay was calibrated with Trolox and results were given as mmol Trolox Eq/g protein. The Oxidative Stress Index (OSI) was defined as the percent ratio of TOS to TAS levels.

\section{Statistical analysis}

Results are given as the mean $\pm \mathrm{SD}$. One-way analysis of variance and post hoc Tukey tests were used for statistical analyses. For statistical analyses, SPSS version 22.0 (IBM Corporation, Armonk, NY, USA) was utilized. $p<0.05$ was considered statistically significant.

\section{Results}

All the torsioned and detorsioned ovaries showed blue--black discoloration macroscopically. Histopathologic evaluation scores are given in Table 1.

This evaluation revealed that ovaries were normal in the sham and $\mathrm{MgSO}_{4}$-sham groups (Figure 2A and $\mathrm{D}$, respectively). Compared to the sham group, increase in edema (black star) and hemorrhage (black arrow) was not statistically significant in the torsion group (Figure 2B) $(p>0.05)$. Increase in these parameters was significant in the torsion-detorsion group compared to the sham group (Figure 2C) $(p<0.05)$.

Decrease in interstitial edema, hemorrhage and inflammatory cells was observed in the $\mathrm{MgSO}_{4}$-torsion group compared to the torsion group (Figure 2E) but differences were not significant $(p>0.05)$.

A significant increase in edema, hemorrhage and inflammatory cells (green arrow) was observed in the torsiondetorsion group compared to the torsion group $(p<0.05)$.

In the torsion- $\mathrm{MgSO}_{4}$-detorsion group (Figure $2 \mathrm{~F}$ ), we observed a statistically insignificant decrease in interstitial edema and hemorrhage and a statistically significant decrease in inflammatory cells compared to the torsion-detorsion group ( $p>0.05$ and $p<0.05$, respectively).

Levels of TOS, TAS, OSI, MDA and GSH and activities of SOD, CAT and GSH-Px of ovarian tissues for each group are presented in Table 2.

Both adnexial torsion and torsion-detorsion caused significant increase in tissue MDA levels $(p<0.05$ and $p<0.001$, respectively). MDA levels were statistically lower in the torsion- $\mathrm{MgSO}_{4}$ group than in the torsion group $(p<0.01)$

Table I Distribution of histopathologic evaluation scores in all groups

\begin{tabular}{llll}
\hline Group & Edema & Hemorrhage & Inflammatory cell \\
\hline Group I & $0.50 \pm 0.83$ & $0.33 \pm 0.5 \mathrm{I}$ & $0.83 \pm 0.98$ \\
Group 2 & $1.16 \pm \mathrm{I} .16$ & $0.83 \pm 0.75$ & $1.00 \pm 01.26$ \\
Group 3 & $2.83 \pm 0.40^{\mathrm{a}, \mathrm{b}}$ & $2.66 \pm 0.5 \mathrm{I}^{\mathrm{a}, \mathrm{b}}$ & $2.80 \pm 0.44^{\mathrm{a}, \mathrm{b}}$ \\
Group 4 & $0.66 \pm 0.8 \mathrm{I}$ & $0.50 \pm 0.83$ & $0.50 \pm 0.83$ \\
Group 5 & $1.00 \pm \mathrm{I} .09$ & $0.50+0.54$ & $0.66 \pm 0.8 \mathrm{I}$ \\
Group 6 & $1.16 \pm 0.75$ & $2.16 \pm 0.75^{\mathrm{a}}$ & $0.83 \pm 0.40^{\mathrm{c}}$ \\
\hline
\end{tabular}

Notes: Group I, sham; Group 2, bilateral ovarian torsion; Group 3, bilateral ovarian torsion-detorsion; Group 4, $\mathrm{MgSO}_{4}$-sham; Group 5, $\mathrm{MgSO}_{4}$-bilateral ovarian torsion; Group 6, bilateral ovarian torsion- $\mathrm{MgSO}_{4}$-detorsion. Data are expressed as the mean \pm standard deviation. ${ }^{a} p<0.05$ when compared to Group I; ${ }^{b} p<0.05$ when compared to Group 2; $c p<0.05$ when compared to Group 3. Data presented as mean \pm SD. Abbreviation: $\mathrm{MgSO}_{4}$, magnesium sulfate. 

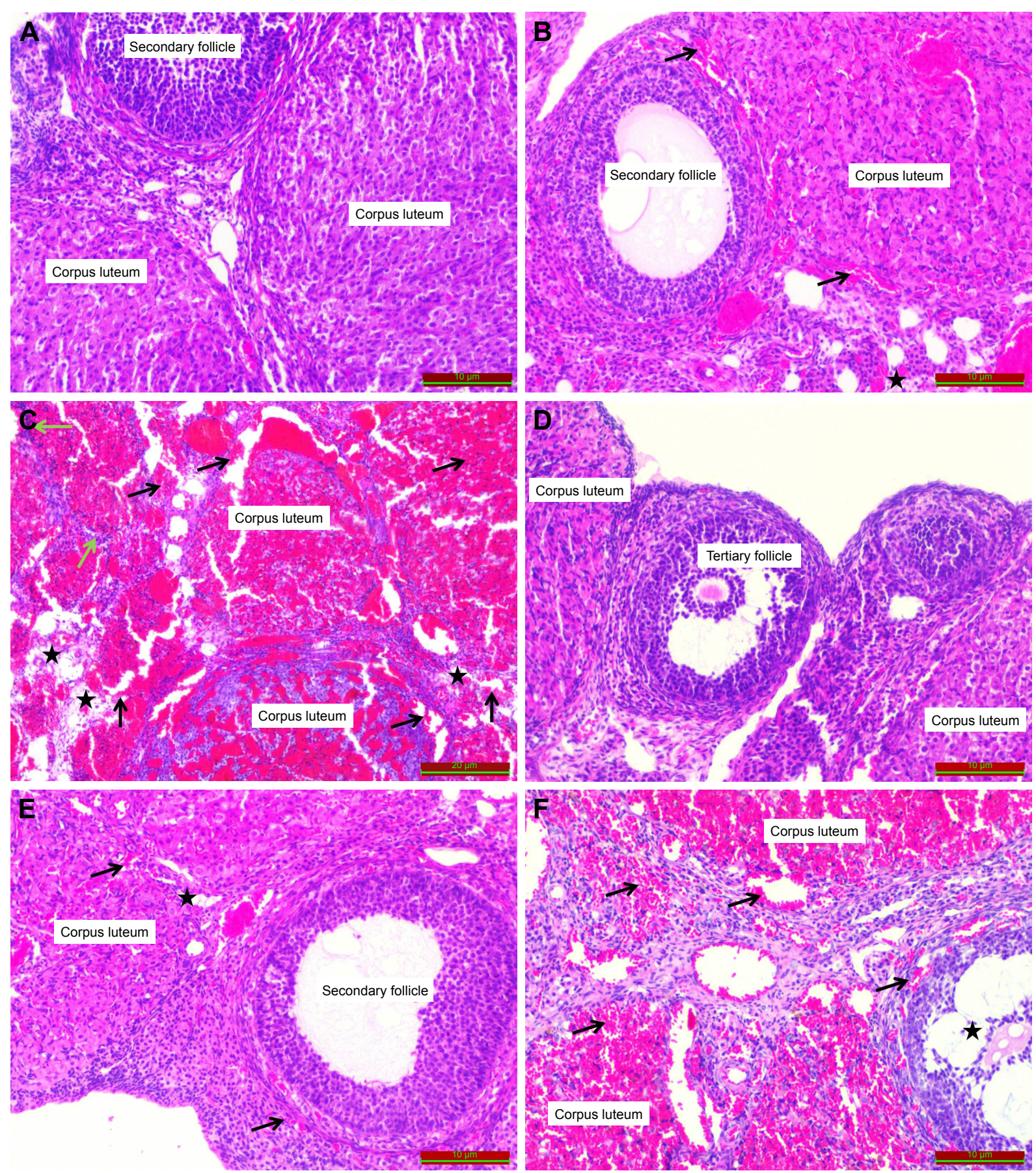

Figure 2 Histopathologic examination of the tissues (hematoxylin and eosin).

Notes: (A) sham group, (B) torsion group, (C) torsion-detorsion group, (D) $\mathrm{MgSO}_{4}$-sham group, (E) $\mathrm{MgSO}_{4}$-torsion group, (F) torsion-MgSO - detorsion group. (A, D) normal ovarian tissue structures in the sham and sham- $\mathrm{MgSO}_{4}$ groups, (B, E) increase in edema (black star) and hemorrhage (black arrow) in the torsion and $\mathrm{MgSO}_{4}$-torsion groups. (C) More prominent edema (black stars), hemorrhage (black arrows) and inflammatory cell infiltration (green arrows) in the torsion-detorsion group, (F) decrease in inflammatory cells with persistence of edema (black star) and hemorrhage (black arrows) in the $\mathrm{MgSO}_{4}$ applied torsion-detorsion group.

Abbreviation: $\mathrm{MgSO}_{4}$, magnesium sulfate.

and were statistically lower in the torsion- $\mathrm{MgSO}_{4}$-detorsion group than in the torsion-detorsion group $(p<0.001)$.

Torsion-detorsion caused a significant decrease in activity of GSH-Px $(p<0.05)$ and the level of GSH $(p<0.001)$ compared to the sham group. Administration of $\mathrm{MgSO}_{4}$ caused a higher tissue activity of GSH-Px and level of GSH in the torsion- $\mathrm{MgSO}_{4}$ group compared to the torsion group $(p<0.05$, for both). We also demonstrated a higher GSH-Px activity and $\mathrm{GSH}$ level in the torsion- $\mathrm{MgSO}_{4}$-detorsion group than in the torsion-detorsion group ( $p<0.05$, for both). 
Table 2 Ovarian tissue TOS, TAS, OSI, MDA and GSH levels and SOD, CAT and GSH-Px activities of all groups

\begin{tabular}{|c|c|c|c|c|c|c|}
\hline Markers & Group I & Group 2 & Group 3 & Group 4 & Group 5 & Group 6 \\
\hline $\mathrm{TOS}\left(\mu \mathrm{mol} \mathrm{H}_{2} \mathrm{O}_{2} \mathrm{Eq} / \mathrm{g}\right.$ protein $)$ & $7.01 \pm 0.48$ & $10.10 \pm 1.68^{*, a}$ & $|2.7| \pm 3.95 * * *, \mathrm{~b}$ & $7.78 \pm 1.00$ & $6.39 \pm 0.65 * *, c$ & $6.36 \pm 0.30 * * *, d$ \\
\hline TAS (mmol Trolax Eq/g protein) & $0.50 \pm 0.09$ & $0.45 \pm 0.03$ & $0.35 \pm 0.12^{*, \mathrm{~b}}$ & $0.52 \pm 0.04$ & $0.42 \pm 0.07$ & $0.37 \pm 0.02$ \\
\hline OSI (arbitrary unit) & $1.44 \pm 0.36$ & $2.22 \pm 0.39$ & $3.90 \pm 1.67^{* * *, b}$ & $1.50 \pm 0.27$ & $1.54 \pm 0.26$ & $1.7 I \pm 0.14 * * *, \mathrm{~d}$ \\
\hline MDA (nmol/g protein) & $6.29 \pm 0.79$ & $8.33 \pm 0.86^{*, a}$ & $10.17 \pm 1.10 * * *, b$ & $4.73 \pm 1.15$ & $5.88 \pm 0.40 * *, c$ & $6.37 \pm 1.92 * * *, \mathrm{~d}$ \\
\hline SOD (U/g protein) & $41.02 \pm 12.93$ & $42.99 \pm 9.48$ & $35.93 \pm 6.61$ & $43.49 \pm 10.19$ & $45.02 \pm 13.35$ & $49.63 \pm 12.29$ \\
\hline CAT $(k / g)$ & $4.04 \pm 0.87$ & $3.04 \pm 0.69$ & $2.4 I \pm 0.44 * *, b$ & $4.12 \pm 0.97$ & $3.62 \pm 0.85$ & $3.14 \pm 0.80$ \\
\hline GSH-Px (U/g protein) & $43.03 \pm 7.67$ & $32.25 \pm 4.38$ & $29.94 \pm 5.50 * . \mathrm{b}$ & $48.79 \pm 11.90$ & $44.39 \pm 5.77^{*, c}$ & $42.55 \pm 7.64^{*, d}$ \\
\hline GSH (nmol/mg protein) & $3.14 \pm 0.52$ & $2.03 \pm 0.30 * * *, a$ & $1.84 \pm 0.15^{* * *, b}$ & $3.23 \pm 0.54$ & $2.77 \pm 0.34^{*, c}$ & $2.58 \pm 0.47^{*, \mathrm{~d}}$ \\
\hline
\end{tabular}

Notes: Group I, sham: Group 2, bilateral ovarian torsion; Group 3, bilateral ovarian torsion-detorsion; Group 4, MgSO -sham; Group 5, MgSO -bilateral ovarian torsion; Group 6, bilateral ovarian torsion- $\mathrm{MgSO}_{4}$-detorsion. Data are expressed as the mean \pm standard deviation. *p $<0.05$; **p $<0.0$ I; *** $p<0.00 \mathrm{I}$. a $\mathrm{Group} 2$ vs $\mathrm{Group} \mathrm{I;}{ }^{\mathrm{b}} \mathrm{Group} 3$ vs Group I; 'Group 5 vs Group 2; ' ${ }^{\circ}$ Group 6 vs Group 3.

Abbreviations: TOS, total oxidant status; TAS, total antioxidant status; OSI, Oxidative Stress Index; MDA, malondialdehyde; GSH, glutathione; SOD, superoxide dismutase; CAT, catalase; GSH-Px, glutathione peroxidase; $\mathrm{MgSO}_{4}$, magnesium sulfate.

Torsion caused an insignificant decrease but torsiondetorsion caused a statistically significant decrease in the activity of catalase $(p<0.05)$. Administration of $\mathrm{MgSO}_{4}$ caused a statistically insignificant increase in catalase levels in all the applied groups. Changes in the activity of SOD were not significant in any of the groups $(p>0.05)$.

We also demonstrated that TOS levels were higher in the torsion and torsion-detorsion groups when compared to the sham group ( $p<0.05$ and $p<0.001$, respectively). TOS levels were lower in the $\mathrm{MgSO}_{4}$ applied torsion and detorsion groups when compared to the torsion only and torsion-detorsion only groups $(p<0.01$ and $p<0.001$, respectively). OSI levels were higher in the torsion-detorsion group when compared to the sham group $(p<0.001) . \mathrm{MgSO}_{4}$ administration caused significantly lower OSI levels in the $\mathrm{MgSO}_{4}$-treated torsion-detorsion group when compared to the torsion-detorsion only group $(p<0.001)$.

\section{Discussion}

Through the advances in organ-preserving surgeries in many fields of medicine, not only ischemic injuries but also reperfusion injuries became important. Studies investigating the prevention of these damages have gained speed. ${ }^{20,21}$ Since management of ovarian torsion by detorsion causes a form of $\mathrm{I} / \mathrm{R}$ injury, measures taken to avoid this damage also became important in the area of gynecology. Ozler et al also demonstrated that surgical detorsion is not sufficient to protect ovarian reserve in an experimental torsion-detorsion model. ${ }^{22}$ Torsion causes ischemic changes, which can be demonstrated by biochemical analysis, in the ovary. Detorsion, as soon as possible, is an important step in the prevention of ovarian damage but alone it does not prevent ovarian damage. By detorsion, reperfusion is established, and reactive oxygen species are created..$^{23}$ In an organism, there is a balance between the production and destruction rate of free radicals and it is known as "oxidative balance". An imbalance that occurs in favor of free radicals is called "oxidative stress". These radicals cause lipid peroxidation in the cell. It is known that the primary mechanism underlying tissue damage is lipid peroxidation and inhibiting or decreasing lipid peroxidation can be a basic strategy in order to prevent tissue injury. MDA levels show oxidative stress and increase through lipid peroxidation. Literature examination revealed that MDA levels were increased in many studies related to I/R injuries. ${ }^{20,24}$ In our study, we determined increased levels of MDA in both the torsion and torsion-detorsion groups compared to the sham group. Significant reduction in MDA levels was observed when $\mathrm{MgSO}_{4}$ was given before torsion and detorsion. As a result of this, we can conclude that $\mathrm{MgSO}_{4}$ can decrease lipid peroxidation and so the tissue injury. Other studies also proved that magnesium deficiency enhances lipid peroxidation and supplementation reduces lipid peroxidation. ${ }^{25,26}$ To prevent the damage caused by reactive oxygen radicals, different biological defense systems are present in cells. CAT, SOD and GSH-Px are the best-known ones. In our study, application of $\mathrm{MgSO}_{4}$ caused statistically non-significant increases in tissue levels of SOD and CAT. We also found that levels of GSH-Px decreased significantly in the torsion-detorsion group and administration of $\mathrm{MgSO}_{4}$ caused significantly higher tissue levels of GSH-Px when compared to untreated groups. This result shows that administration of $\mathrm{MgSO}_{4}$ increases biological defense mechanisms against reactive oxygen radicals.

GSH is a substrate for GSH-Px and has antioxidant activity in many cells. We demonstrated that both torsion and torsion-detorsion caused a significant decrease in tissue levels of GSH. Application of $\mathrm{MgSO}_{4}$ increased the GSH levels significantly in all groups. Since synthesis of GSH is 
magnesium dependent, the antioxidant property of magnesium might be also related to the GSH pathway.

OSI is a marker for the degree of oxidative stress and is the combined ratio between TOS and TAS. In our study, torsion-detorsion caused a significant increase in the level of TOS and OSI. Administration of $\mathrm{MgSO}_{4}$ caused significantly lower tissue levels of TOS and OSI in the torsion- $\mathrm{MgSO}_{4}-$ detorsion group.

Histologic examination revealed that torsion-detorsion caused a statistically significant increase in the scores of edema, hemorrhage and inflammatory cells. Administration of $\mathrm{MgSO}_{4}$ caused a decrease in all scores but only the decrease in inflammatory cells was significant. Inflammatory cells are important in tissue damage.

The effects of magnesium on I/R injury of different organs have been investigated. Studies demonstrated that administration of magnesium reduced renal I/R injury in rat experimental models. ${ }^{27}$ Kao et al demonstrated that $\mathrm{MgSO}_{4}$ significantly reduced the oxidative stress and inflammatory response caused by bilateral lower limb I/R in rats. ${ }^{8}$ Data from different studies support that brain damage caused by hypoxia and radiation-induced oxidative stress of the spinal cord could be diminished by $\mathrm{MgSO}_{4} \cdot{ }^{28,29} \mathrm{Kim}$ et al showed that administration of magnesium before reperfusion of liver transplantation significantly reduced blood lactate levels. ${ }^{30}$ Kaptanoglu et al demonstrated that administration of magnesium reduced the I/R injury on fetal rat skin. ${ }^{31} \mathrm{~A}$ free radical reducing effect of magnesium in a coronary occlusion reperfusion model was demonstrated by Garcia et al. ${ }^{32}$ It was also demonstrated that magnesium reduces the lactate and MDA levels after cerebral ischemia. ${ }^{33}$ It was shown that application of Lomodex- $\mathrm{MgSO}_{4}$ prior to detorsion increases semen quality and fertility. ${ }^{34}$ There are many other beneficial effects of magnesium. It is known that magnesium can inhibit thrombus formation. ${ }^{35}$ Ravn et al demonstrated that magnesium can inhibit arterial thrombus formation. ${ }^{36}$ Magnesium also increases red cell deformability. ${ }^{37}$ After the discovery of the importance of calcium in ischemic cell death, calcium antagonists have come into focus for protection from ischemic damage. Magnesium is a physiological calcium antagonist. It competes with calcium ions for ion channels or receptor binding. Inhibition of calcium entry into the cell by magnesium may serve an additional benefit in ovarian $\mathrm{I} / \mathrm{R}$ injury.

Magnesium also causes blood vessel dilatation. It can reduce infarct size in ischemia. ${ }^{38} \mathrm{We}$ did not try to explore these effects of magnesium in our study, but these properties of magnesium may provide additional benefits in the case of torsion-detorsion induced ovarian damage.

\section{Conclusion}

This is the first study to investigate the effects of magnesium on I/R induced injury of the ovary. Magnesium is an easily accessible inexpensive drug. Obstetricians and gynecologists are familiar with it and can use the drug safely. In the light of previous reports and our study, we can enounce that $\mathrm{MgSO}_{4}$ may save the ovary from $\mathrm{I} / \mathrm{R}$ injury. A limitation of our study is the absence of long-term influences of $\mathrm{MgSO}_{4}$. Further studies are needed to define the best effective dose, duration, other mechanisms of action and long-term effects before its usage in clinical practice.

\section{Author contributions}

ECK and SBK designed the study after a detailed literature search for ischemia/reperfusion injury and effects of magnesium. OB, ECK and FGB performed the experiments. FGB performed the biochemical analyses, and wrote the results and methods of analysis. NK performed the histologic evaluation, wrote the results and also took the photographs of the tissue specimens. ECK wrote the article with input from all authors. ECK arranged and submitted the article.

\section{Disclosure}

The authors report no conflicts of interest in this work.

\section{References}

1. Poonai N, Poonai C, Lim R, Lynch T. Pediatric ovarian torsion: case series and review of the literature. Can J Surg. 2013;56(2):103-108.

2. Oelsner G, Cohen SB, Soriano D, Admon D, Mashiach S, Carp H. Minimal surgery for the twisted ischaemic adnexa can preserve ovarian function. Hum Reprod. 2003;18(12):2599-2602.

3. Carden DL, Granger DN. Pathophysiology of ischaemia-reperfusion injury. J Pathol. 2000;190(3):255-266.

4. Türk E, Karaca İ, Ozcinar E, et al. The effect of hypothermia on adnexal torsion/detorsion injury in a rat ovary model. J Pediatr Surg. 2015;50(8):1378-1381.

5. Ozkisacik S, Yazici M, Gursoy H, Culhaci N. Does gradual detorsion protect the ovary against ischemia-reperfusion injury in rats? Pediatr Surg Int. 2014;30(4):437-440.

6. Sahin Ersoy G, Eken M, Tal R, et al. N-acetylcysteine leads to greater ovarian protection than enoxaparin sodium in a rat ovarian torsion model. Reprod Biomed Online. 2016;33(1):93-101.

7. Yildirim N, Yigitturk G, Sahingoz Yildirim AG, et al. Octreotide protects ovary against ischemia-reperfusion injury in rats: evaluation of histological and biochemical parameters. J Obstet Gynaecol Res. 2015;41(10):1591-1597.

8. Kao MC, Jan WC, Tsai PS, Wang TY, Huang CJ. Magnesium sulfate mitigates lung injury induced by bilateral lower limb ischemia-reperfusion in rats. J Surg Res. 2011;171(1):e97-e106.

9. Lee CY, Jan WC, Tsai PS, Huang CJ. Magnesium sulfate mitigates acute lung injury in endotoxemia rats. $J$ Trauma. 2011;70(5):1177-1185.

10. Fawcett WJ, Haxby EJ, Male DA. Magnesium: physiology and pharmacology. Br J Anaesth. 1999;83(2):302-320.

11. Ohkawa H, Ohishi N, Yagi K. Assay for lipid peroxides in animal tissues by thiobarbituric acid reaction. Anal Biochem. 1979;95:351-358.

12. Ellman G. Tissue sulfhydryl groups. Arch Biochem Biophys. 1959;82: $70-77$. 
13. Aebi H. Catalase in vitro assay methods. Methods Enzymol. 1984;105: 121-126.

14. Paglia DE, Valentine WN. Studies on the quantitative and qualitative characterisation of erytrocyte glutathione peroxidase. J Lab Clin Med. 1967;70:158-169.

15. Sun Y, Oberley LW, Li Y. A simple method for clinical assay of superoxide dismutase. Clin Chem. 1988;34:497-500.

16. Durak I, Yurtaslanı Z, Canbolat O, Akyol O. A methodological approach to superoxide dismutase (SOD) activity assay based on inhibition of nitroblue tetrazolium (NBT) reduction. Clin Chim Acta. 1993;214: 103-104.

17. Lowry OH, Rosebrough NJ, Farr AL, Randall RJ. Protein measurement with Folin phenol reagent. J Biol Chem. 1951;193:265-275.

18. Erel O. A new automated colorimetric method for measuring total oxidant status. Clin Biochem. 2005;38:1103-1111.

19. Erel O. A novel automated direct measurement method for total antioxidant capacity using a new generation, more stable ABTS radical cation. Clin Biochem. 2004;37:277-285

20. Yaman Tunc S, Agacayak E, Goruk NY, et al. Protective effects of honokiol on ischemia/reperfusion injury of rat ovary: an experimental study. Drug Des Devel Ther. 2016;10:1077-1083.

21. Kılıç Y, Özer A, Tatar T, et al. Effect of picroside II on hind limb ischemia reperfusion injury in rats. Drug Des Devel Ther. 2017;11: 1917-1925.

22. Ozler A, Turgut A, Soydinç HE, et al. The biochemical and histologic effects of adnexal torsion and early surgical intervention to unwind detorsion on ovarian reserve: an experimental study. Reprod Sci. 2013;20(11):1349-1355.

23. Taskin O, Birincioglu M, Aydin A, et al. The effects of twisted ischaemic adnexa managed by detorsion on ovarian viability and histology: an ischaemia-reperfusion rodent model. Hum Reprod. 1998; 13(10):2823-2827.

24. Ergun Y, Koc A, Dolapcioglu K, et al. The protective effect of erythropoietin and dimethylsulfoxide on ischemia-reperfusion injury in rat ovary. Eur J Obstet Gynecol Reprod Biol. 2010;152(2):186-190.

25. Kramer JH, Misík V, Weglicki WB. Magnesium-deficiency potentiates free radical production associated with postischemic injury to rat hearts: vitamin E affords protection. Free Radic Biol Med. 1994;16(6): 713-723

26. Ariza AC, Bobadilla N, Fernández C, Muñoz-Fuentes RM, Larrea F, Halhali A. Effects of magnesium sulfate on lipid peroxidation and blood pressure regulators in preeclampsia. Clin Biochem. 2005;38(2): $128-133$.
27. Akan M, Ozbilgin S, Boztas N, et al. Effect of magnesium sulfate on renal ischemia-reperfusion injury in streptozotocin-induced diabetic rats. Eur Rev Med Pharmacol Sci. 2016;20(8):1642-1655.

28. Maulik D, Qayyum I, Powell SR, Karantza M, Mishra OP, DelivoriaPapadopoulosm M. Post-hypoxic magnesium decreases nuclear oxidative damage in the fetal guinea pig brain. Brain Res. 2001;890(1): 130-136.

29. Peker S, Abacioglu U, Sun I, Konya D, Yüksel M, Pamir NM. Prophylactic effects of magnesium and vitamin $\mathrm{E}$ in rat spinal cord radiation damage: evaluation based on lipid peroxidation levels. Life Sci. 2004; 75(12):1523-1530.

30. Kim JE, Jeon JP, No HC, et al. The effects of magnesium pretreatment on reperfusion injury during living donor liver transplantation. Korean J Anesthesiol. 2011;60(6):408-415.

31. Kaptanoglu AF, Arca T, Kilinc K. Magnesium sulfate protects fetal skin from intrauterine ischemia reperfusion injury. Arch Dermatol Res. 2012;304(7):529-532.

32. Garcia LA, Dejong SC, Martin SM, Smith RS, Buettner GR, Kerber RE Magnesium reduces free radicals in an in vivo coronary occlusionreperfusion model. J Am Coll Cardiol. 1998;32(2):536-539.

33. Bariskaner H, Ustun ME, Ak A, Yosunkaya A, Ulusoy HB, Gurbilek M. Effects of magnesium sulfate on tissue lactate and malondialdehyde levels after cerebral ischemia. Pharmacology. 2003;68(3):162-168.

34. Adivarekar PK, Bhagwat SS, Raghavan V, Bandivdekar AH. Effect of Lomodex-MgSO(4) in the prevention of reperfusion injury following unilateral testicular torsion: an experimental study in rats. Pediatr Surg Int. 2005;21(3):184-190.

35. Shechter M. The role of magnesium as antithrombotic therapy. Wien Med Wochenschr. 2000;150(15-16):343-347.

36. Ravn HB, Kristensen SD, Hjortdal VE, Thygesen K, Husted SE. Early administration of intravenous magnesium inhibits arterial thrombus formation. Arterioscler Thromb Vasc Biol. 1997;17:3620-3625.

37. Schauf B, Becker S, Abele H, Klever T, Wallwiener D, Aydeniz B. Effect of magnesium on red blood cell deformability in pregnancy. Hypertens Pregnancy. 2005;24(1):17-27.

38. Ravn HB, Moeldrup U, Brookes CI, et al. Intravenous magnesium reduces infarct size after ischemia/reperfusion injury combined with a thrombogenic lesion in the left anterior descending artery. Arterioscler Thromb Vasc Biol. 1999;19(3):569-574.

\section{Publish your work in this journal}

Drug Design, Development and Therapy is an international, peerreviewed open-access journal that spans the spectrum of drug design and development through to clinical applications. Clinical outcomes, patient safety, and programs for the development and effective, safe, and sustained use of medicines are the features of the journal, which

\section{Dovepress}

has also been accepted for indexing on PubMed Central. The manuscript management system is completely online and includes a very quick and fair peer-review system, which is all easy to use. Visit http://www.dovepress.com/testimonials.php to read real quotes from published authors. 